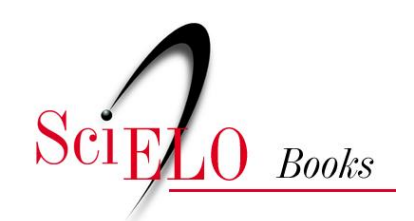

\title{
Ética y responsabilidad social y su aplicación en gestión de herramientas administrativas en el Centro de Privación Provisional de la Libertad, Guayaquil-Ecuador
}

\author{
José Miguel Peláez Freire \\ José Rojas Bedoya
}

\section{SciELO Books / SciELO Livros / SciELO Libros}

PELÁEZ FREIRE, J.M., and ROJAS BEDOYA, J. Ética y responsabilidad social y su aplicación en gestión de herramientas administrativas en el Centro de Privación Provisional de la Libertad, Guayaquil-Ecuador. In: IZA VILLACÍS, V.A., ed. Persona, educación y filosofía: reflexiones desde la educación universitaria [online]. Quito: Editorial Abya-Yala, 2018, pp. 85-103. ISBN: 978-997810-493-4. https://doi.org/10.7476/9789978104934.0006.

\section{International license.}

Todo o conteúdo deste trabalho, exceto quando houver ressalva, é publicado sob a licença Creative Commons Atribição 4.0.

Todo el contenido de esta obra, excepto donde se indique lo contrario, está bajo licencia de la licencia Creative Commons Reconocimento 4.0. 


\section{Ética y responsabilidad social y su aplicación en gestión de herramientas administrativas en el Centro de Privación Provisional de la Libertad, Guayaquil-Ecuador}

José Miguel Peláez Freire ${ }^{1}$ José Rojas Bedoya

\section{Resumen}

La presente investigación es extensionista. El tipo de investigación posee un enfoque mixto ya que se combinan elementos cuantitativos propios de las ciencias administrativas y cualitativos propios de las ciencias sociales, al tratarse de las relaciones que se van a establecer entre los participantes, el alcance de la investigación es de tipo explicativo, ya que no solo se recrean las características visibles a simple vista en el proceso de capacitación, sino que se explica el comportamiento, las conductas y las transformaciones que se evidencian en los sujetos. el diseño es no experimental porque no se trata de un experimento,

1 Candidato a Doctorado en Teología Civil - UPB- Medellín. Magister en Gerencia Educativa - Magister en Teología Docente de la Pastoral Universitaria, Universidad Politécnica Salesiana de Guayaquil. jpelaez@ups.edu.ec

2 Doctor en Teología, Pontificia Universitas Angelus- Roma, Italia. Profesional del Área de Bienestar del Aprendiz - SENA - Medellín - Colombia. joserojasbedoya@gmail.com 
sino de contribuir a la gestión del conocimiento con herramientas administrativas para formar capacidades, habilidades gerenciales en los internos privados de libertad, desde un enfoque humanístico.

Persona y empresa actualmente no son sinónimos de generar cambios, la empresa se ubica en primer lugar dejando de lado el valor del ser humano y su influencia como valor en la empresa, esta ponencia pretende aportar a tener una mirada más humana al ámbito organizacional empresarial, partiendo desde una experiencia formativa con personas privadas de la libertad, facilitándoles herramientas que les permita en un futuro hacer empresa desde una visión más humana, pero no solo como un beneficio económico y productivo.

Palabras claves: Responsabilidad social, ética social, gestión, administración, economía de comunión.

\section{Abstract}

The present investigation is extensionist. The type of research has a mixed approach since it combines quantitative elements typical of the administrative and qualitative sciences of the social sciences, when dealing with the relationships that are to be established among the participants, the scope of the research is of an explanatory type , Since not only the characteristics visible to the naked eye are recreated in the training process, but also the behavior, behaviors and transformations that are evidenced in the subjects, the design is non-experimental because it is not an experiment, But to contribute to the management of knowledge in administrative tools to build capacities in inmates deprived of liberty.

Keywords: Social responsibility, social ethics, management, administration, economy of communion.

\section{Introducción}

El Centro de Privación Provisional de la Libertad de GuayaquilEcuador (CPPLG) cuenta con 400 personas privadas de libertad, el 80\% 
es por pago alimenticio a sus hijos y el $20 \%$ por contravenciones por escándalos en la vía pública. Así mismo el 90\% no son profesionales.

El tiempo de permanencia promedio para los apremios es de 30 a 60 días, mientras que para las contravenciones es de 10 a 21 días. La edad promedio de 22 a 42 años, lo que quiere decir que es una población relativamente joven la que hay que reincorporar a la sociedad, máxime cuando se conoce además que el 10\% de la población interna posee profesión, el 50\% tiene algún tipo de oficio y el 40\% culminó el bachillerato. Un sistema de capacitación mediante las herramientas de la administración permitirá formar capacidades, desarrollar habilidades, destrezas y mejorar el nivel de vida de los sujetos, una vez reincorporados a la sociedad.

Kant fomenta una lectura marcada en la dignidad humana en la que propone aspectos relevantes como es "la constatación empírica de la problemática en estudio ha develado la siguiente situación problematizante, que sin constituir el problema en sí lo condiciona, y consiste en que a pesar de los esfuerzos realizados por las instituciones educativas por contribuir a un mayor conocimiento y desarrollo de habilidades en función de la transformación social de los sujetos involucrados, en muchos casos la realidad ha estado caracterizada por una débil articulación de estas, como de los sectores vulnerables, por lo que la realización de acciones con carácter integrador e interdisciplinar son aisladas, de forma irregular, sistémicas, en tanto no se sustentan en una estructura secuenciada y dinámica para promover la construcción de saberes de los sujetos involucrados a partir de su propia realidad, lo que se refleja de forma negativa en lo cognitivo y en su modo de actuación.

Estas limitaciones van provocando la inexistencia de un proceso para propiciar conocimientos y desarrollo de habilidades, desde las herramientas de la Administración.

Urge entonces iniciar un trabajo dirigido, a propiciar un cambio en la actitud de las personas que son infractoras, apoyado por acciones que involucren a familiares y demás miembros de la sociedad. 
Se debe tomar en cuenta el valor de la persona, es decir desde su dignidad, hablar de productividad y economía e incluso de la misma sociedad, se debe partir de la persona y de sus valores intrínsecos, en la que no es una máquina de producción o solo entes de producción.

Kant distingue claramente entre "valor" y "dignidad". Concibe la "dignidad" como un valor intrínseco de la persona moral, la cual no admite equivalentes. La dignidad no debe ser confundida con ninguna cosa, con ninguna mercancía, dado que no se trata de nada útil ni intercambiable o provechoso. Lo que puede ser reemplazado y sustituido no posee dignidad, sino precio. Cuando a una persona se le pone precio se la trata como a una mercancía. "Persona es el sujeto cuyas acciones son imputables (...) Una cosa es algo que no es susceptible de imputación” (Michelini, 2010, p. 36). De ahí que la ética, según Kant, llegue sólo hasta "los límites de los deberes recíprocos de los hombres" (p. 36).

En cuanto ser dotado de razón y voluntad libre, el ser humano es un fin en sí mismo, que, a su vez, puede proponerse fines. Es un ser capaz de hacerse preguntas morales, de discernir entre lo justo y lo injusto, de distinguir entre acciones morales e inmorales, y de obrar según principios morales, es decir, de obrar de forma responsable. Los seres moralmente imputables son fines en sí mismos, esto es, son seres autónomos y merecen un respeto incondicionado. El valor de la persona no remite al mercado ni a apreciaciones meramente subjetivas (de conveniencia, de utilidad, etcétera), sino que proviene de la dignidad que le es inherente a los seres racionales libres y autónomos.

En consecuencia, la autonomía moral es el concepto central con que Kant caracteriza al ser humano y constituye el fundamento de la dignidad humana: "La autonomía, es, pues, el fundamento de la dignidad de la naturaleza humana y de toda naturaleza racional".

Kant resalta el valor del ser humano, lo ve desde su dimensión integral, ve el valor de sí mismo en su dignidad, se ve valorada que toda acción del ser humano tiene por mínima que sea aportara a 
toda gestión que realice en favor de otro ser humano, la capacidad de encontrarse con otros y de relacionarse lo hace ver mejor y más ser humano y por ende su dignidad se verá engrandecida.

El ser humano no es solo útil desde un punto de vista de producción económica, es útil por el simple hecho de existir, sostener que el ser humano no es "algo", sino "alguien", rompe el paradigma de cómo se lo ve actualmente, comparado con todo como si se tratase de un objeto o una máquina de hacer, mas no de Ser.

Los aportes de Stob, tendrán dos momentos importantes: primero, la ética como parte de la individualidad, y segundo, el desenvolvimiento del ser humano en esa misma relación.

Podemos decir que la tesis central de Stob es: "La ética se enfoca sobre el individuo porque sólo el individuo es verdaderamente personal y por lo tanto un auténtico agente moral” (Roldán, 2005). Trata de eludir la crítica hacia el latente individualismo que surge de sus palabras y entonces dice: "Es obvio que no estoy abogando por el tipo de Individualismo que sostiene que uno es responsable sólo por aquello que ha hecho con sus propias manos o en su propia persona". ${ }^{3}$ En el encuentro con el otro, podemos decir que el individuo conoce su propia alteridad, ya que el principio de la ética social nos ayuda a conocernos como personas en relación con los demás.

El proyecto llevó a cabo una metodología que fue empleada bajo una sistematización teórica-práctica, consultando fuentes bibliográficas como libros, periódicos y documentos de instituciones,

3 La ética social se ocupa de la conducta moral de los individuos así como de las realidades colectivas e individuales. Su preocupación por el individuo es, sin embargo, de una clase especial; es calificada socialmente. Contempla al individuo no meramente como la personalidad centrada que es, no específicamente como uno que responde sin ninguna mediación explícita al prójimo que, en su soledad o en su pluralidad indeterminada, lo confronta directamente. Más bien lo contempla como a quien da una respuesta individual a una comunidad personalista 
empleando el análisis y la síntesis, la inducción y la deducción, para procesar la información. Los resultados se enmarcan en la importancia de la incidencia desde principios éticos teológicos y de responsabilidad social y su aplicación al conocimiento en Gestión de herramientas administrativas para el Centro de Privación Provisional de la Libertad, Guayaquil-Ecuador, por lo que estos actores deben involucrarse y socializar internamente los alcances de las mismas.

El debate debe generarse a partir de analizar en qué medida la incidencia de principios éticos teológicos y de responsabilidad social involucra a la sociedad para dar un equilibrio entre la gestión administrativa y desarrollo humano. Concluyendo que adoptar estrategias que generen la concientización necesaria, apoyándose de herramientas existentes dejadas de utilizar o que no han migrado tecnológicamente. Los objetivos del proyecto están alineados en la problemática de una Gestión Empresarial que carece de una ética teológica y de responsabilidad social integral, vivida desde una economía de comunión.

\section{Responsabilidad social y dignidad humana}

Según Díaz en su texto al hablar de la dignidad considera y sostiene que el ser humano tiene una dignidad que lo sobrepasa por ello plantea:

Ya hemos hablado sobre la dignidad de la persona y su relación con la empresa. La segunda es responsable sólo si tutela permanentemente la primera. Ahora bien, las empresas tienen la responsabilidad imperativa de ofrecerle al trabajador oficios que lo dignifiquen y que al mismo tiempo creen beneficios de crecimiento social en términos de valores útiles para el progreso del mercado y de la sociedad. A este respecto afirma la Iglesia: "La Doctrina social ha subrayado la contribución que las empresas ofrecen a la valoración del trabajo, al crecimiento del sentido de responsabilidad personal y social, a la vida democrática, a los valores humanos útiles para el progreso del mercado y de la sociedad" (cfr. Díaz, 2009, p. 63).

Posibilitar el desarrollo integral significa que todas las dimensiones de lo humano son puestas en el lugar de reflexión de la vida empresarial. 
El trabajo humano es un escenario de desarrollo. El reto de las empresas hoy consiste en conciliar justicia y equidad laboral que permitan un adecuado desarrollo personal del trabajador, con la productividad y la supervivencia propias del quehacer empresarial. Una empresa socialmente responsable crea beneficio social desde sus actores constitutivos (empleados, administradores, clientes, proveedores), hasta la comunidad social y global que impacta con su producto de manera directa o indirecta (Díaz, 2009, p. 64).

Este impacto debe ser medible en términos de valor en tanto que dentro de la empresa no se debe aprender a ser sólo un buen cerrajero, un buen telefonista, un buen contador (técnica), sino llegar a ser buen ser humano (ética). La implicación significativa de la acción ética es trascendente en otros sujetos de la sociedad e inmanente a la propia persona que trabaja en la empresa.

El desafío de construir una empresa debe centrarse en el valor del ser humano, urge en este tiempo donde la realidad más que nunca se convierte muy difícil el volver y cambiar el pensamiento de aquellos que la dirigen en una gerencia por departamentos y áreas a fines, ya que la visión empresarial es solo medir los efectos de calidad y productividad y consolidar los niveles de producción, calidad que se ve en el cumplimiento y el bienestar de la empresa, mas no de los clientes internos que forman parte de ella.

La responsabilidad social en América Latina no solo corresponde a un ente empresarial sino a toda una sociedad. La preocupación por los impactos sociales, ambientales y económicos que genera una organización o empresa se ha acentuado en los últimos tiempos. ¿Estamos provocando un desarrollo que asegura el bienestar de todos con los que nos relacionamos? ¿Estamos contribuyendo al calentamiento global y a incrementar el riesgo de la vida en nuestro planeta? Nuestro despliegue, ¿contribuye a generar nuevas oportunidades de empleo y de negocios que facilitan la reducción de la pobreza? ¿Qué estamos haciendo para mitigar, reducir o eliminar esos riesgos? ¿Es suficiente llevar adelante acciones filantrópicas? 
Nos encontramos en un momento de la historia de la humanidad en el que nuestro comportamiento, los valores que llevamos a la práctica a través de las maneras que producimos, y, en general, nuestra ética, adquieren una significación crucial. Hoy no se puede ser socialmente responsable si no aspiramos a un desarrollo sostenible; es decir, si nuestra cultura, nuestras conductas diarias y nuestras lógicas económicas, ambientales y sociales no se encuentran coherentemente alineadas. Nos enfrentamos al desafío de plasmar desde nuestras empresas y organizaciones una ética de responsabilidad social (Peinado-Vara, 2011).

En un inicio es importante señalar que esta toma de conciencia y de reflexión sobre la responsabilidad que las empresas tienen sobre la sociedad ha atrasado en llegar. Es de vital importancia para su efecto probablemente queda mucho camino por transitar y, lo que es más, está por ver si en el contexto de "crisis" se mantiene conservar la opinión de que las responsabilidades de las empresas no son únicamente un ente económico. Será muy importante que estas estrategias sean mantenidas incluso en los momentos más complicados, esto dará una autentica medida de hasta qué punto se interioriza estas ideas.

En ningún caso pueda considerarse que estas normas, que no dejan de ser de perfil voluntario, puedan ser similares de otras obligaciones para con la sociedad. Por otro lado la importancia de comprender el requerimiento de respetar a las personas, ya sean clientes internos y externos, accionistas y trabajadores, entre otros.

Por último, es anhelado que los sistemas de gestión que integran las declaraciones de valores, los códigos de ética, las normas o políticas de empresa entre otras, realmente se asuman como propias en las organizaciones y se adopten todas las medidas proactivas necesarias, para que así se trasmitan verdaderamente a la sociedad, y no termine siendo la responsabilidad social empresarial una mera declaración de buenas personas y bien intencionada. 


\section{El proyecto y sus productos}

El proyecto permitió la sistematización teórica de los referentes que sustentan el proceso de gestión del conocimiento en herramientas de la administración, para los privados de libertad. así como el respectivo diagnóstico sobre las necesidades de capacitación en herramientas administrativas que presentan los internos privados de libertad, para finalmente generar un plan de acciones que mediante sus componentes (Cursos, talleres, módulos o materias) contribuya a formar capacidades, habilidades, destrezas en lo sujetos sobre el proceso de gestión del conocimiento en herramientas de administración.

\section{Criterios de seguimiento y evaluación del proyecto}

El seguimiento y evaluación del proyecto es de gran importancia para su éxito, no se puede esperar al final para evaluar, por lo que se llevará a cabo por los colaboradores y estudiantes involucrados a partir del diagnóstico inicial como punto de partida, la evaluación de seguimiento se realizará a partir de los resultados e indicadores planteados, así como las técnicas que se emplearán en el transcurso de la ejecución del proyecto en cada módulo o materia que se imparta y se presentará una evaluación e informe final con los resultados e impactos que evidencian transformación en comparación con el diagnóstico inicial, así como la ejecución del presupuesto asignado. 
Cuadro 1

De acompañamiento

\begin{tabular}{|c|c|c|}
\hline Objetivos específicos & Indicador & Meta \\
\hline $\begin{array}{l}\text { 1. Sistematizar los elemen- } \\
\text { tos teóricos que fundamen- } \\
\text { tan el proceso de gestión } \\
\text { del conocimiento en herra- } \\
\text { mientas administrativas. }\end{array}$ & $\begin{array}{l}\text { Cantidad de materiales } \\
\text { elaborados y presentados } \\
\text { por los investigadores. } \\
\% \text { que se utilizan en las } \\
\text { acciones de capacitación } \\
\text { que se realizan. }\end{array}$ & $\begin{array}{l}\text { Fundamentar con los mate- } \\
\text { riales de apoyo, la difusión } \\
\text { de la información. }\end{array}$ \\
\hline $\begin{array}{l}\text { 2. Implementar un sistema } \\
\text { de acciones en herramien- } \\
\text { tas administrativas que de } \\
\text { forma secuenciada y diná- } \\
\text { mica contribuya a formar } \\
\text { capacidades en los internos } \\
\text { privados de libertad. }\end{array}$ & $\begin{array}{l}\text { Número final de Módulos o } \\
\text { Materias que se impartirán. } \\
\% \text { de acciones y/o cursos, } \\
\text { talleres planificados. } \\
\% \text { de ellos realiza- } \\
\text { dos realmente. } \\
\% \text { de acciones propias de la } \\
\text { institución docente. } \\
\% \text { en que contribuye la UPS } \\
\text { al desarrollo de las acciones. } \\
\% \text { de acciones por parte } \\
\text { del resto de las institucio- } \\
\text { nes participantes. }\end{array}$ & $\begin{array}{l}\text { El sistema de acciones que } \\
\text { se presenta satisface las } \\
\text { expectativas de los partici- } \\
\text { pantes en un } 90 \% \text {. }\end{array}$ \\
\hline $\begin{array}{l}\text { 3. Evaluar las transforma- } \\
\text { ciones ocurridas a través del } \\
\text { seguimiento y monitoreo } \\
\text { del proceso. }\end{array}$ & $\begin{array}{l}\text { No. total de visitas realiza- } \\
\text { das al Centro de Privación } \\
\text { Provisional de la Libertad. } \\
\text { No. de internos capacita- } \\
\text { dos realmente. } \\
\% \text { de ellos que son mujeres. } \\
\% \text { de ellos que son hombres. } \\
\% \text { de asistencia a los cursos. } \\
\% \text { de internos que culmi- } \\
\text { nan los cursos iniciados. } \\
\text { (Retención) } \\
\text { Reforzamiento de valores } \\
\text { como puntualidad, discipli- } \\
\text { na. (Por módulo) } \\
\% \text { de participa- } \\
\text { ción individual. } \\
\text { No de compromisos } \\
\text { asumidos. } \\
\text { Habilidades adqui- } \\
\text { ridas en herramien- } \\
\text { tas administrativas. }\end{array}$ & $\begin{array}{l}\text { Al menos el } 50 \% \text { de los in- } \\
\text { ternos culminan los cursos } \\
\text { de capacitación. } \\
\text { Lograr al menos el } 80 \% \\
\text { de satisfacción. }\end{array}$ \\
\hline
\end{tabular}




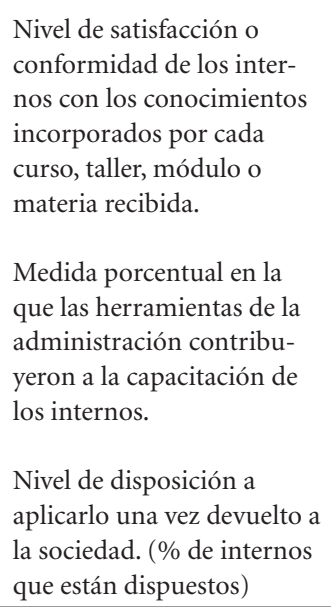

Elaboración: Proyecto de Vinculación de la Universidad Politécnica SalesianaGuayaquil

\section{Cuadro 2 \\ De desarrollo}

\begin{tabular}{|c|l|l|}
\hline \multicolumn{2}{|l|}{} & $\begin{array}{l}\text { Implementar un sistema de acciones en herramientas ad- } \\
\text { Objetivistrativas, para la gestión del conocimiento de los in- } \\
\text { fractores del Centro de Privación Provisional de la Libertad, } \\
\text { Guayaquil, que de forma sistémica, secuenciada y dinámica } \\
\text { contribuya a la transformación cognitiva y del modo de ac- } \\
\text { tuación de los sujetos involucrados en función del desarrollo } \\
\text { comunitario y local. }\end{array}$ \\
\hline \multirow{2}{*}{ Indicadores } & 1 & 25 Infractores se benefician de las capacitaciones. \\
\cline { 2 - 3 } & 2 & $\begin{array}{l}\text { 9 Personas entre docentes, estudiantes y personal de Centro } \\
\text { de Privación Provisional de libertad mejoran sus habilidades } \\
\text { en herramientas administrativas. }\end{array}$ \\
\cline { 2 - 4 } & 3 & $\begin{array}{l}\text { 25 personas mejoran sus habilidades sociales producto a la } \\
\text { gestión del conocimiento en herramientas administrativas. }\end{array}$ \\
\hline \multirow{2}{*}{ Objetivo específico 1} & $\begin{array}{l}\text { Sistematizar los elementos teóricos que fundamentan } \\
\text { el proceso de gestión del conocimiento en herramien- } \\
\text { tas administrativas. }\end{array}$ \\
\hline \multirow{2}{*}{ Indicadores } & 4 & $\begin{array}{l}\text { Cantidad de materiales elaborados y presentados por } \\
\text { los investigadores. }\end{array}$ \\
\cline { 2 - 3 } & 5 & $\begin{array}{l}\text { 50\% que se utilizan en las acciones de capacitación que } \\
\text { se realizan. }\end{array}$ \\
\hline
\end{tabular}




\begin{tabular}{|c|c|c|}
\hline \multicolumn{2}{|c|}{ Objetivo específico 2} & $\begin{array}{l}\text { Implementar un sistema de acciones en herramientas admi- } \\
\text { nistrativas que de forma secuenciada y dinámica contribuya }\end{array}$ \\
\hline \multirow{3}{*}{ Indicadores } & 6 & Número final de Módulos o Materias que se impartirán. \\
\hline & 7 & $\begin{array}{l}50 \% \text { de acciones y/o cursos, talleres planificados. } \\
50 \% \text { de ellos realizados realmente. }\end{array}$ \\
\hline & 8 & $\begin{array}{l}\% \text { de acciones propias de la institución docente. } \\
\% \text { en que contribuye la UPS al desarrollo de las acciones. }\end{array}$ \\
\hline & 9 & $\begin{array}{l}\% \text { de acciones por parte del resto de las institucio- } \\
\text { nes participantes. }\end{array}$ \\
\hline \multicolumn{2}{|c|}{ Objetivo específico 3} & $\begin{array}{l}\text { Evaluar las transformaciones ocurridas a través del segui- } \\
\text { miento y monitoreo del proceso. }\end{array}$ \\
\hline Indicadores & 10 & $\begin{array}{l}\text { No total de visitas realizadas al Centro de Privación Provisio- } \\
\text { nal de Libertad. }\end{array}$ \\
\hline & 11 & $\begin{array}{l}\text { No de internos capacitados realmente. } \\
\% \text { de ellos que son mujeres. } \\
\% \text { de ellos que son hombres. } \\
\% \text { de asistencia a los cursos. }\end{array}$ \\
\hline & 12 & $\%$ de internos que culminan los cursos iniciados.(Retención) \\
\hline & 13 & $\begin{array}{l}\text { Reforzamiento de valores como puntualidad, disciplina. } \\
\text { (Por módulo) } \\
\text { \% de participación individual. }\end{array}$ \\
\hline & 14 & $\begin{array}{l}\text { No de compromisos asumidos. } \\
\text { Habilidades adquiridas en herramientas administrativas. }\end{array}$ \\
\hline & 15 & $\begin{array}{l}\text { Nivel de satisfacción o conformidad de los internos con los } \\
\text { conocimientos incorporados por cada curso, taller, módulo } \\
\text { o materia recibida. }\end{array}$ \\
\hline & 16 & $\begin{array}{l}\text { Medida porcentual en la que las herramientas de la adminis- } \\
\text { tración contribuyeron a la capacitación de los internos. }\end{array}$ \\
\hline & 17 & $\begin{array}{l}\text { Nivel de disposición a aplicarlo una vez devuelto a la socie- } \\
\text { dad. (\% de internos que están dispuestos) }\end{array}$ \\
\hline
\end{tabular}

Elaboración: Proyecto de Vinculación de la Universidad Politécnica Salesiana, Guayaquil 


\section{Aportes de la Ética Teológica al proyecto}

Siendo un proyecto diseñado en la Universidad Politécnica Salesiana sede Guayaquil-Ecuador, con carácter humanístico, promoción humana y evangelizador se sostiene desde los aportes de una Ética Teológica que busca la recta valoración del ser humano desde el enfoque moral sostén importante en los principios de la Doctrina Social de la Iglesia, especialmente en sus cartas encíclicas, la Populorum Progressio del Papa Pablo VI sobre "el desarrollo de los pueblos" en sus numerales 17, 18 donde se plantea un progreso de los pueblos pero desde el desarrollo de la persona como un deber comunitario, el estar al servicio de los demás y en la recta vivencia de los valores desde una escala en la que el eje central es la persona.

\section{Deber comunitario}

17.

Pero cada uno de los hombres es miembro de la sociedad, pertenece a la humanidad entera. No se trata sólo de este o aquel hombre, sino que todos los hombres están llamados a un pleno desarrollo. Nacen, crecen y mueren las civilizaciones. Pero, como las olas del mar durante el flujo de la marea van avanzando, cada una un poco más, sobre la arena de la playa, de igual manera la humanidad avanza por el camino de la historia. Herederos de pasadas generaciones, pero beneficiándonos del trabajo de nuestros contemporáneos, nos hallamos obligados para con todos, y no podemos desentendernos de los que todavía vendrán a aumentar más el círculo de la familia humana. La solidaridad universal, que es un hecho a la vez que un beneficio para todos, es también un deber (Pablo, 1967, p. 5).

Es indudable que los valores han sido importantes en el magisterio, sus aportes han dado el inicio de una visión positiva de que la vivencia de los valores de la persona es posible.

\section{Escala de valores}

18.

Este crecimiento personal y comunitario correría peligro, si la verdadera escala de valores se alterase. Es legítimo el deseo de lo 
necesario, y trabajar para conseguirlo es un deber: el que no quiera trabajar, que no coma.[17] Pero la adquisición de bienes temporales puede convertirse en codicia, en deseo de tener cada vez más y llegar a la tentación de acrecentar el propio poder. La avaricia de las personas, de las familias y de las naciones puede alcanzar tanto a los más pobres como a los más ricos, suscitando, en unos y en otros, un materialismo que los ahoga (Pablo, 1967, p. 5).

El progreso exige una acción de conjunto en aspectos económicos, sociales y culturales. No se puede circunscribir a una evolución económica, sino que toca mirar al mayor potencial económico en su totalidad. Todo ser humano, toda persona posee el derecho de superarse y desplegar sus dones y crecer en cualquier contexto dentro de la sociedad. Cada persona es miembro de la sociedad indudablemente se debe a una comunidad, es de considerar que su trabajo es una necesidad, pero hay que evitar la voracidad, la avaricia, el fuerte deseo de tener y poseer donde lo ético y moral pasan a segundo plano. Un desarrollo autentico implica los más altos valores de la persona donde este se convierte en el principio y centro de toda gestión.

El Papa Benedicto XVI hace alusión de las consecuencias que tiene el asumir una mirada al ser humano y lo expresa en su carta encíclica Caritas in Veritate donde sostiene la importancia del bien común partiendo desde el Ser persona, se comprende que la promoción humana en beneficio de una sociedad marcada por la indiferencia es necesario el saber compartir no solo los bienes materiales, sino el bien personal dentro de este el conocimiento. En su numeral 7 enfatiza que el bien de una persona es el bien de los demás, lo que nos proyecta a una vivencia de una Economía de Comunión en las empresas.

7.

Hay que tener también en gran consideración el bien común. Amar a alguien es querer su bien y trabajar eficazmente por él. Junto al bien individual, hay un bien relacionado con el vivir social de las personas: el bien común. Es el bien de ese 'todos nosotros', formado por individuos, familias y grupos intermedios que se unen en comu- 
nidad social [4]. No es un bien que se busca por sí mismo, sino para las personas que forman parte de la comunidad social, y que sólo en ella pueden conseguir su bien realmente y de modo más eficaz. Desear el bien común y esforzarse por él es exigencia de justicia y caridad. Trabajar por el bien común es cuidar, por un lado, y utilizar, por otro, ese conjunto de instituciones que estructuran jurídica, civil, política y culturalmente la vida social, que se configura así como polis, como ciudad. Se ama al prójimo tanto más eficazmente, cuanto más se trabaja por un bien común que responda también a sus necesidades reales (XVI, Encíclica Caritas in Vertitate, 2009).

Benedicto XVI pretende asentar los valores más nobles que deben guiar el ejercicio de la economía, la política, las relaciones sociales, la técnica y los avances científicos, los medios de comunicación y otros temas de notabilidad en nuestra sociedad. Todas estas circunstancias deben estar al servicio del hombre, y deben servir para el progreso de todos los hombres y de todos los pueblos y de la persona humana, en todas sus extensiones, no sólo los aspectos materiales, sino también culturales y espirituales. No pueden estar sólo en función del beneficio personal, del beneficio de unos pocos, en deterioro de la miseria y empobrecimiento de otros. La encíclica esboza muchos temas en profundidad y requiere una atenta mirada sobre todo por parte de empresarios, economistas, políticos, trabajadores sindicales, y demás que con su trabajo diario y su esfuerzo intentan trabajar por el bien común, por la superación de la crisis económica y tienen una propuesta solidaria hacia los más pobres.

En la encíclica se dan criterios para dar frente y discernir los retos y obstáculos que plantean asuntos tan actuales como la globalización, el mercado financiero, la crisis económica, el problema del hambre en el mundo, la inmigración, el avance de la técnica y de la biotecnología y otras de más interés.

La ética social procede de la experiencia fusionada de alguien, de las personas y culturas con quien se relaciona en la cotidianidad, pero se debe partir de una pregunta base: 
¿De qué se ocupa la ética social? Afirma Stob: La ética social se ocupa de la conducta moral de los individuos así como de las realidades colectivas y súper-individuales. Su preocupación por el individuo es, sin embargo, de una clase especial; es calificada socialmente. Contempla al individuo no meramente como la personalidad centrada que es, no específicamente como uno que responde sin ninguna mediación explícita al prójimo que, en su soledad o en su pluralidad indeterminada, lo confronta directamente. Más bien lo contempla como a quien da una respuesta individual a una comunidad super-individual Para Stob, hay cuatro tipos de problemas que caen dentro del campo de la ética social. A saber: Primero: El individuo y el Estado. El problema central aquí es cómo armonizar el interés del individuo y el de la comunidad. El problema surge porque los centros de vida y los propósitos individuales y colectivos, aunque independientes, están siempre en tensión; la libertad y la espontaneidad sostenidas por el uno son contrarrestadas por la autoridad y el orden sostenidos por el otro. La tarea moral aquí consiste en establecer arreglos sociales de tal forma que puedan evitar el desequilibrio en el conflicto Segundo. Relación individuo y organización o comunidad. Los puntos principales que surgen aquí se refieren a la existencia o a la no existencia de una base común para la deliberación y la acción, y la realidad y el significado de tales cosas como la responsabilidad conjunta, la culpa colectiva, la excepción de los efectos de la decisión mayoritaria por razón de conciencia, y otros parecidos Tercero: Relaciones entre organizaciones y comunidades. Típico de este tipo de problemas es la relación Iglesia y Estado. Aquí se deben tratar temas de asuntos económicos y políticos y formas de organización social: socialista, capitalista, comunista, Estado benefactor. Cuarto: Consecuencias de la pluralidad y de la unidad. Son los diversos modelos de las relaciones entre la Iglesia y la sociedad. En la Edad Media, la sociedad occidental logró cierta unidad bajo la hegemonía de la Iglesia que había alcanzado la cúspide del poder. Con el Renacimiento y la Reforma se da la diversidad religiosa y el pluralismo cultural y social (Roldán, 2006, p. 44).

La calidad de la ética es impulsada por una moral individual que se comprueba por la forma de actuar correcta o incorrecta, la ética social se centra más en lo que puede considerarse como un proceder adecuado de las personas como un todo, más que un comportamiento individual. 
Sin embargo, ya que las personas distinguen las cosas de manera diferente, y las numerosas culturas favorecen creencias diferentes, lo que se considera adecuado para uno no necesariamente tiene serlo para otra persona. Por ello, la definición de la ética social como un incondicional puede ser bastante complejo.

Para que esta ética social sea más efectiva se requiere una aplicación no solo de los conocimientos empresariales, se requiere un compromiso en conjunto con los valores del ser humano y es ahí donde la propuesta de Chiara Lubich de "Economía de Comunión" en la empresas tiene su valor agregado para el favorecimiento no solo en el desarrollo económico de la empresa como tal, sino de quienes la conforman. es así que:

Las empresas que adhieren al proyecto "Economía de Comunión", si bien operan en el mercado, se proponen como su razón de ser, hacer de la actividad económica un lugar de encuentro en el sentido más profundo del término, un lugar de "comunión". Una comunión entre los que tienen bienes y oportunidades económicas y los que no las tienen; comunión entre todos los sujetos que participan en diferentes modos en la misma actividad. Si es cierto que muchas veces la economía contribuye a crear barreras entre las clases sociales, estas empresas se comprometen en cambio: a) a destinar parte de las utilidades para aliviar directamente las necesidades más urgentes de personas que atraviesan situaciones de dificultad económica. b) a promover dentro de la empresa y con los clientes, proveedores, con la competencia, con la comunidad local e internacional, con la administración pública, relaciones leales y de confianza, con la mirada puesta en el interés general; c) a vivir y a difundir la cultura del dar, de la paz, de la legalidad, de atención al ambiente (hay que ser solidarios también con la Creación), todo esto dentro y fuera de la empresa (Lubich, 1999, p. 61).

Es con estos criterios que la gestión empresarial adquiere más que una responsabilidad social, es un compromiso con la comunidad toda, donde la Ética Teológica es aplicada en su máxima expresión siendo timonel y guía de una responsabilidad social bien llevada y como tal de la mano de una Economía del dar por el bien común, Economía que busca redescubrir la presencia de Dios en la Gestión 
102

Empresarial en beneficio del ser humano, el cual obra dentro de ella para un beneficio de la actividad productiva, surgiendo de esta manera una economía que aporte desde la reflexión como un llamado a la conversión y a la exaltación de una conciencia de la misma Gestión Empresarial la cual con una visión cristiana favorece la relación con Dios y la comprensión con los hombres.

\section{Conclusiones}

La aplicación de herramientas administrativas a los privados de la Libertad tuvo éxito ya que los treinta estudiantes que iniciaron pudieron culminar el proyecto, obteniendo un certificado avalado por la Universidad Politécnica Salesiana sede Guayaquil, a través de su Proyecto de Vinculación con la Sociedad, en coordinación con el Ministerio de Justicia del Ecuador resaltando que el hacer empresa no es solo emprender, administrar, gerenciar un negocio y por ende hacer dinero y convertirse en entes productivos, hay algo más que es la materialización la misma que deteriorará la dignidad humana, y que como personas de empresas se tiene el deber ser, por aplicar y vivir coherentemente una responsabilidad social tanto a quienes la conforman, así como aquellas que se ven beneficiados de ella.

Finalmente, la Economía de la Comunión se vislumbra como la respuesta que requieren las empresas que hacen desde sus negocios un medio de encuentro con Dios, consigo mismo, con los demás y con la creación.

\section{Bibliografía}

Díaz, D. A. (junio de 2009). La responsabilidad social empresarial en la persepectiva de la Iglesia Católica. Ciencias Estratégicas, 17(21), 63. Disponible en: https://goo.gl/keJWUq.pdf (mayo 2017).

Lubich, C. (1999). ¿Es posible una teoría económica que humanice la economía? Cultura y Sociedad, 4. Disponible en: https://goo.gl/tnm$\mathrm{NgW}$ (agosto 2017). 


\section{3}

Michelini, D.J. (2010). Dignidad humana en Kant y habermas. Estudios de Filosofía práctica e historia de las ideas, 12, 41-49. Disponible en: https://goo.gl/Csxhc5 (mayo 2017).

Pablo, V. (1967). Encíclica Popularum Progressio. vatican.va. Disponible en: https:/goo.gl/sphRDT

Peinado-Vara, A. V. (2011). La responsabilidad social de la empresa en América Latina. Fondo Multilateral de Inversiones (FOMIN). Disponible en: https://goo.gl/raZjPC (junio 2017).

Roldán, A. F. (2005). ¿Qué entendemos por ética social? www.teologos.com. ar, 10. Disponible en: https://goo.gl/3c9dhd

Roldán, A. F. (2006). ¿Qué entendemos por ética social? dos divisiones sobre el tema (Vol. 5). Disponible en: https://goo.gl/V5mHWq (agosto 2017).

XVI, B. (2009). Caritas in Veritate. vatican.va. Disponible en: https://goo.gl/ UxMz5C (junio 2017). 